\title{
Improvement of replication fidelity by certain mesalazine derivatives
}

\author{
CLEMENS HONEDER $^{1,2}$, CHRISTOPH CAMPREGHER ${ }^{1,2}$, BETTINA ZENS ${ }^{1,2}$, \\ THERESA SCHARL ${ }^{3,4}$ and CHRISTOPH GASCHE ${ }^{1,2}$
}

\author{
${ }^{1}$ Christian Doppler Laboratory for Molecular Cancer Chemoprevention, ${ }^{2}$ Division of Gastroenterology \\ and Hepatology, Department of Internal Medicine 3, Medical University of Vienna; ${ }^{3}$ ACIB GmbH, \\ c/o Department of Biotechnology, University of Natural Resources and Life Sciences; ${ }^{4}$ Department \\ of Statistics and Probability Theory, University of Technology, Vienna, Austria
}

Received July 29, 2011; Accepted September 19, 2011

DOI: 10.3892/ijo.2012.1381

\begin{abstract}
Epidemiological evidence on the chemopreventive activity of mesalazine against colitis-associated cancer has accumulated in recent years. Together with the variety of mesalazine molecular antitumor effects this has prompted the development of novel mesalazine derivatives. The objective of this study was to test five novel derivatives (compounds 2-14, 2-17, 2-28, 2-34L, 2-39) for their effect on cell proliferation, their capability to scavenge superoxide anions, to induce a cell cycle arrest and to improve replication fidelity in cultured colorectal cells. Compound 2-14 was identified as the strongest inhibitor of cell proliferation and functioned as a potent superoxide scavenger, as did 2-17 and 2-34L. 2-14 induced a G2/M-arrest in HCT116 and a G0/G1-arrest in HT29 cells. 2-17 caused a G0/G1-arrest and 2-34L a G2/M-arrest in HT29 cells. 2-17 and 2-34L reduced mutation rates at a (CA)13 repeat in a dose-dependent fashion. These data suggest that certain mesalazine derivatives share important antitumor effects. From this experimental profile compounds 2-17 and 2-34L both improve replication fidelity, which is biologically relevant not only for colitis-associated cancer but also potentially for individuals with hereditary nonpolyposis colorectal cancer.
\end{abstract}

\section{Introduction}

Sulfasalazine was discovered for the treatment of rheumatoid arthritis and ulcerative colitis (UC) almost 70 years ago (1). In the following decades aminosalicylates became the most

Correspondence to: Dr Christoph Gasche, Christian Doppler Laboratory for Molecular Cancer Chemoprevention, Medical University of Vienna, Department of Internal Medicine 3, Division of Gastroenterology and Hepatology, Waehringer Guertel 18-20, A-1090 Vienna, Austria

E-mail: christoph.gasche@meduniwien.ac.at

Key words: colorectal cancer, chemoprevention, microsatellite instability, replication fidelity important drugs for the treatment of UC. Since mesalazine (5-aminosalicylic acid; 5-ASA) was identified as the active moiety of sulfasalazine in 1977 (2), aminosalicylate therapy, with the exception of improved galenics, was not improved substantially. Mesalazine still is the drug of choice for the maintenance of remission and the treatment of mild flares in UC patients. In recent years epidemiological and molecular evidence on mesalazine's chemopreventive properties has accumulated (3-5). Besides the anti-inflammatory properties of mesalazine including inhibition of nitric oxide synthase (6), downregulation of cyclo-oxygenase-2 (COX-2) (7), scavenging of reactive oxygen species (ROS) (8), inhibition of nuclear factor- $\kappa \mathrm{B}(\mathrm{NF}-\kappa \mathrm{B})$ pathway (9) and antimicrobial properties (10), molecular studies demonstrated interference with c-myc expression (11), EGFR-signaling (12), peroxisome proliferatoractivated receptor- $\gamma($ PPAR- $\gamma)$-signaling (13), the Wnt/ $\beta$-catenin pathway (14) and induction of apoptosis (15). Our laboratory data showed that mesalazine improves replication fidelity (16) and induces a p53-independent S-phase arrest (17). These studies fueled the development of novel and hopefully more effective mesalazine derivatives, not only for treatment of UC but also for chemoprevention of colorectal cancer (CRC). The aim of this study was to evaluate five such novel mesalazine derivatives for important antitumor effects in vitro.

\section{Materials and methods}

Cell lines. HCT116 (hMLH1 mutant) and HT29 (p53 mutant) colorectal cancer cells were obtained from ATCC (Manassas, VA). HCT116 A2.1 is a reporter cell line for replication errors, harboring a pIREShyg2-EGFP/CA13 plasmid (18). Cells were grown in monolayers in Iscove's modified Dulbecco's medium (IMDM; Gibco/Invitrogen, Karlsruhe, Germany) and 10\% fetal bovine serum (FBS, Biochrom, Berlin, Germany) at $37^{\circ} \mathrm{C}$ and $5 \% \mathrm{CO}_{2}$. HCT116 A2.1 cells were grown in IMDM medium containing $200 \mu \mathrm{g} / \mathrm{ml}$ Hygromycin B.

Reagents. All five compounds tested were provided by Giuliani S.p.A., Milan, Italy (Fig. 1). 5-amino-N-hydroxy-2-methoxybenzamide (2-14) was dissolved in IMDM at $4 \mathrm{mmol} / \mathrm{l}$. 5-amino-2,3-dihydrobenzofuran-7-carboxyclic acid (2-17) 
was dissolved in IMDM at $20 \mathrm{mmol} / 1$. 6-amino-2,2-dimethylbenzo [1,3]dioxin-4-one (2-28) was dissolved in methanol at $100 \mathrm{mmol} / \mathrm{l}$ and then added to IMDM at up to $1 \mathrm{mmol} / \mathrm{l}$. (-)-3-(4-aminophenyl)-2-methoxypropionic acid (2-34L) was dissolved in IMDM at $100 \mathrm{mmol} / \mathrm{l}$. (R, S)2-ethoxy-3-(4'aminophenyl)propionic acid (2-39) was dissolved in IMDM at $40 \mathrm{mmol} / \mathrm{l}$. Mesalazine (Giuliani S.p.A.) was dissolved in IMDM at $40 \mathrm{mmol} / \mathrm{l}$. After the dissolution of the compounds the culture media were $\mathrm{pH}$ adjusted to 7.4 with $\mathrm{NaOH}$ and then sterile filtered. Lucigenin (Merck, Darmstadt, Germany) and MTT (Sigma, Germany) were dissolved in PBS ${ }^{-\mathrm{Ca} / \mathrm{Mg}}$ (Gibco/ Invitrogen). Bromodeoxyuridine (BrdU, Sigma) was dissolved in dimethyl sulfoxide (DMSO, Sigma).

Cell proliferation assay. HCT116 (8x10 $10^{3}$ cells/well) and HT29 $\left(1 \times 10^{4}\right.$ cells/well) were seeded in 96-well plates. Twenty-four hours later cells were treated with mesalazine $(0-40 \mathrm{mmol} / \mathrm{l})$, 2-14 (0-4 mmol/l), 2-17 (0-20 mmol/l), 2-28 (0-1 mmol/l), 2-34L $(0-100 \mathrm{mmol} / \mathrm{l})$ and $2-39(0-40 \mathrm{mmol} / \mathrm{l})$ for $48 \mathrm{~h}$. After treatment, cells were washed with phosphate buffered saline (PBS, Gibco/ Invitrogen) and incubated for $3 \mathrm{~h}$ with $100 \mu \mathrm{l}$ IMDM containing $0.5 \mathrm{mg} / \mathrm{ml} \mathrm{MTT}$. Cells were lysed in $10 \%$ sodium dodecyl sulfate (SDS) and $0.01 \mathrm{~N}$ hydrochloric acid ( $\mathrm{HCl}$ ) for $24 \mathrm{~h}$. Absorbance was measured at $570 \mathrm{~nm}$ in a microplate reader (Anthos Labtec HT2). Each assay was carried out in 6 wells per concentration and cell line.

Superoxide scavenging assay. The isolation and activation of neutrophils was performed as described (19). Briefly, $1 \times 10^{6}$ polymorphonuclear leukocytes (PMNs) per sample were activated using $50 \mathrm{ng} / \mathrm{ml}$ phorbol 12-myristate 13 -acetate (Sigma). Superoxide $(\mathrm{O} \cdot 2)$ release in the presence of the compounds was determined by lucigenin-enhanced chemiluminescence on a tube luminometer (Lumat LB9507, Berthold). $2000 \mathrm{U} / \mathrm{ml}$ superoxide dismutase (SOD, Sigma) was used as control. The experiments were done in triplicates.

Cell cycle analysis. For the quantification of the S-phase population, subconfluent cells were pulsed with $10 \mu \mathrm{M}$ BrdU for $60 \mathrm{~min}$ prior to fixation in $70 \%$ ice cold ethanol. Fixed cells were treated with $2 \mathrm{M} \mathrm{HCl}$ and $0.1 \mathrm{M}$ sodium borate was used to neutralize any residual acid before incubation with a monoclonal anti-BrdU antibody (Santa Cruz Biotechnology, Santa Cruz, CA). Subsequently cells were incubated with a FITClabeled secondary anti-mouse antibody (Molecular Probes/ Invitrogen), incubated in propidium iodide (10 $\mu \mathrm{g} / \mathrm{ml}$ in PBS) and analyzed by flow cytometry (FACScan, Becton-Dickinson) as described (17). Experiments were done in triplicates.

Flow cytometry-based assay for replication fidelity. Analysis of mutations was performed as previously described (18). Briefly, 1x10 ${ }^{3}$ non-fluorescent HCT116 A2.1 cells, harboring an EGFPbased frameshift mutation reporter plasmid (pIREShyg2-EGFP/ CA13), were sorted on a FACSAria using CloneCyt Plus sorting technology (Becton-Dickinson). $24 \mathrm{~h}$ later cells were treated with different concentrations of the compounds and analyzed by flow cytometry after incubation for 7 days. The counts of low fluorescent M1 cells, high fluorescent M2 cells and the combined counts of M1 and M2 cells were expressed as frac-

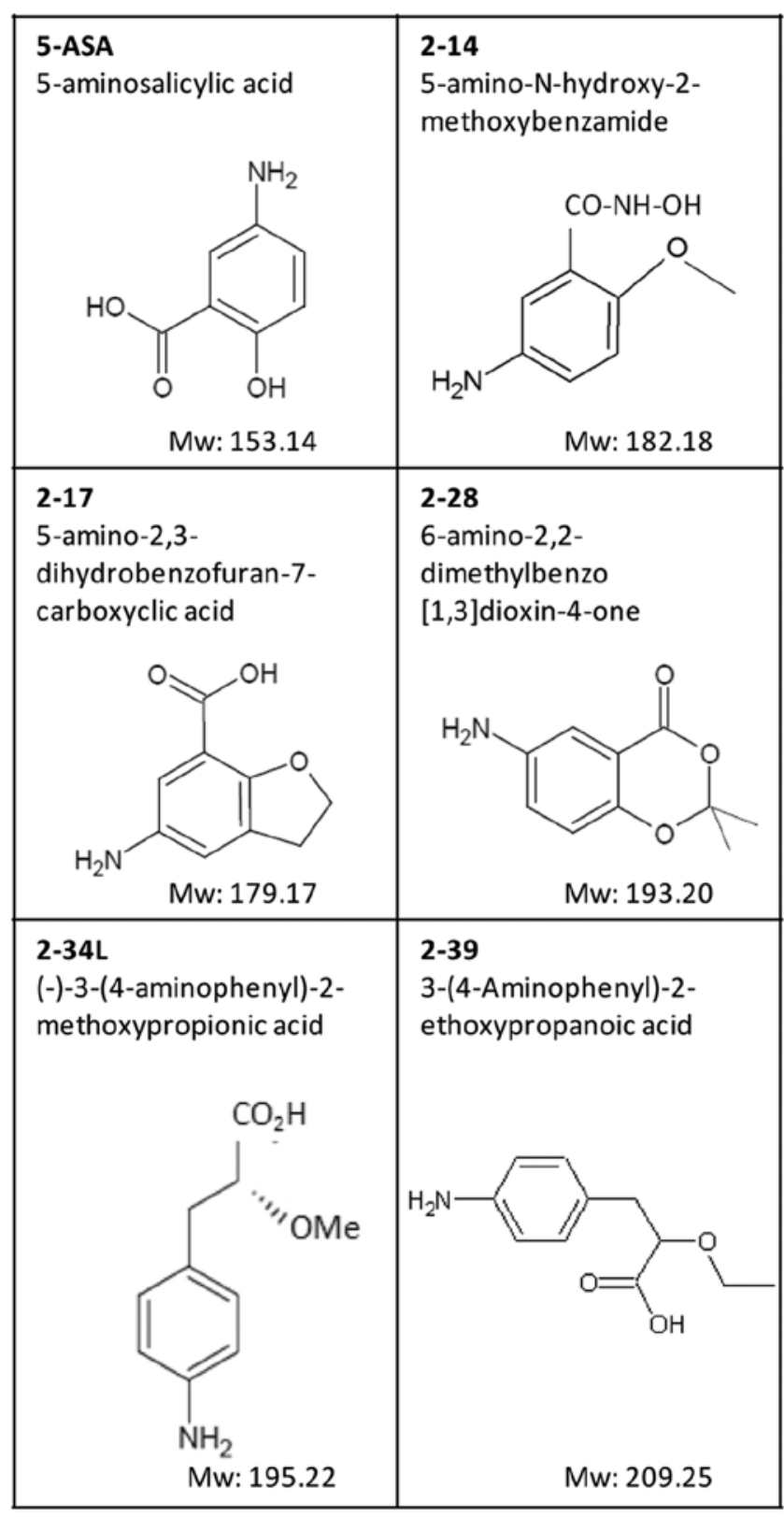

Figure 1. Abbreviations, names, structure formulas and molecular weights of mesalazine and the derivatives.

tions of the total cell number in culture. Mutation rates were calculated as previously described (20).

Western blotting. Cell lysates and DNA-bound fractions were obtained as previously described (17). Western blot analysis was performed on 4-12\% NuPAGE gels (Invitrogen). All antibodies for immunoblotting were diluted in PBS with $3 \%$ bovine serum albumin and $0.03 \% \mathrm{NaN}_{3}$. Antibodies used included: Mouse monoclonal antibody (mAb) anti-p53 DO7 (Calbiochem, Vienna, Austria); rabbit polyclonal antibody (pAb) antiphopsho-p53Ser15; pAb anti-RPA; pAb anti-claspin (all Cell Signaling, Frankfurt am Main, Germany), mAb anti- $\beta$-actin (Santa Cruz Biotechnology) and mAb anti-Histone H3 (Upstate Biotechnology). 

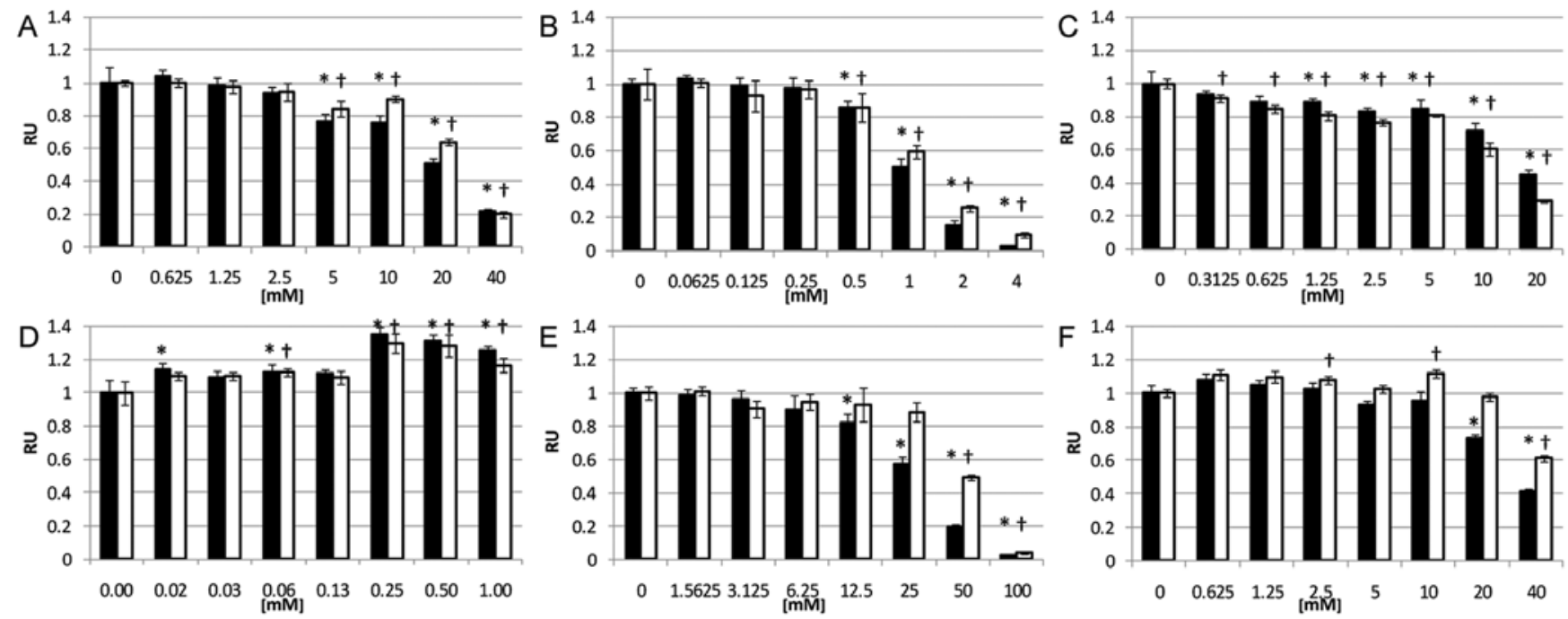

Figure 2. Dose-response effect of (A) 5-ASA and novel derivatives (B) 2-14, (C) 2-17, (D) 2-28, (E) 2-34L, (F) 2-39 on cell proliferation. HCT116 (solid bars) and HT29 (open bars) cells were plated in 96-well microplates. Twenty-four hours after seeding cells were treated with the compounds for $48 \mathrm{~h}$. The effects on cell proliferation were measured by MTT-assay. Data indicate mean \pm SD and were analyzed by one-way ANOVA and Tukey's HSD for post-hoc analysis (HCT116: control vs. treated cells, ${ }^{*} \mathrm{p} \leq 0.001$; HT29: control vs. treated cells, ${ }^{\dagger} \mathrm{p} \leq 0.001$ ).

Statistical analysis. Data are represented as mean of obtained measures of one of the experiments. The half maximal inhibitory concentration $\left(\mathrm{IC}_{50}\right)$ was calculated online, using BioDataFit 1.02 (Chang Bioscience, Castro Valley, CA) for the creation of a linear model. One-way analysis of variance (ANOVA) with post-hoc analysis using Tukey's honest significant difference was used for statistical analysis of the results. P-values $<0.05$ were regarded as statistically significant. Cochran-Armitage trend tests were used to compare mutant fractions across different concentrations of the compounds. Mutation rates were calculated using two methods: the method of the mean and the maximum likelihood method.

\section{Results}

Mesalazine derivatives interfere with cell proliferation. MTT assay was used to evaluate the inhibitory effect on cell proliferation in colon epithelial cells treated with mesalazine derivatives. All compounds except for 2-28 induced a dose-dependent reduction of cell proliferation in HCT116 and HT29 cells (Fig. 2). Compound 2-14 was the most effective inhibitor and reduced cell proliferation at 10 magnitudes lower than mesalazine. The specific $\mathrm{IC}_{50}$ were as follows: $1.7 \mathrm{mM}$ (HCT116) and $1.9 \mathrm{mM}$ (HT29) for 2-14; $18 \mathrm{mM}$ (HCT116) and $13 \mathrm{mM}$ (HT29) for 2-17; $42 \mathrm{mM}$ (HCT116) and $53 \mathrm{mM}$ (HT29) for 2-34L and $35 \mathrm{mM}$ (HCT116) and $57 \mathrm{mM}$ (HT29) for 2-39. These concentrations were indicative for the following experiments, but had to be adapted due to different incubation times, which influenced cytotoxicity of the compounds.

2-14, 2-17 and 2-34L are potent superoxide scavengers. ROS such as superoxide $\left(\mathrm{O}_{2}^{-}\right)$are thought to be the major causative factors of inflammation-driven carcinogenesis (21). Mesalazine is a potent scavenger of such radicals, and its anti-mutagenic properties are partially attributed to this property (3). Structural similarities between mesalazine and its derivatives suggest that

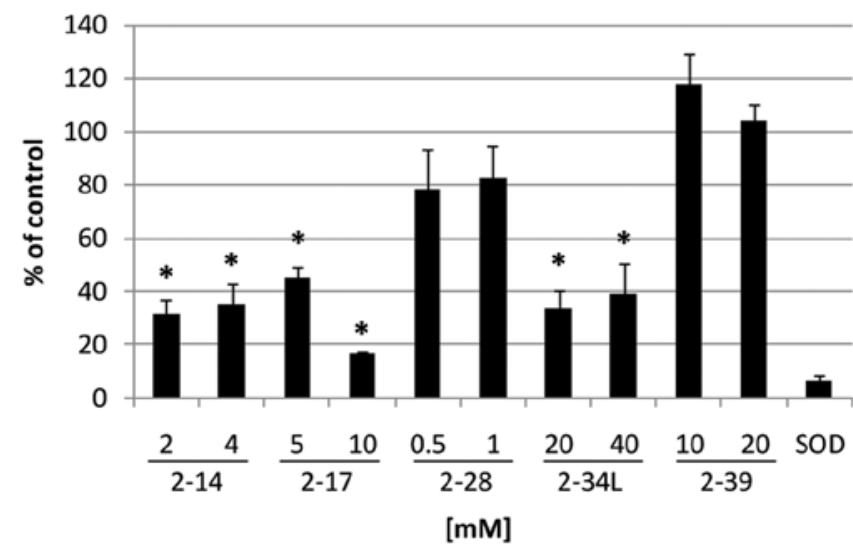

Figure 3. Superoxide scavenging. PMA-activated neutrophils were used as $\mathrm{O}_{2}$ donors and $\mathrm{O}_{2}{ }^{-}$concentrations were measured after $15 \mathrm{~min}$ by lucigeninamplified chemiluminescence. $2000 \mathrm{U} / \mathrm{ml}$ SOD served as control. Data are presented in percent of control (mean $\pm \mathrm{SD}$ ) and were compared by one-way ANOVA using Tukey's honest significant difference for post-hoc analysis. * $\mathrm{p}<0.05$.

some of the new compounds might be $\mathrm{O}_{2}^{-}$-scavengers as well. To test this hypothesis we performed a lucigenin-enhanced chemiluminescence assay for the detection of $\mathrm{O}_{2}^{-}$released by PMNs. 2-17 showed the best scavenging effect, reducing the $\mathrm{O}_{2}^{-}$level to $16 \%$ of the control value at the concentration of $10 \mathrm{mM}$ (p<0.001; Fig. 3). 2-14 and 2-34L caused moderate $\mathrm{O}_{2}^{-}$ scavenging (to $35 \%, \mathrm{p}=0.004$ and $38 \%$ of the control, $\mathrm{p}=0.007$, respectively) at the concentrations tested. 2-28 and 2-39 did not exhibit such properties at any concentrations tested. Taken together these results suggest that the mesalazine derivatives do not scavenge $\mathrm{O}_{2}^{-}$to the same extent.

Effects of mesalazine derivatives on cell cycle progression. Our previous research showed that mesalazine induces a replication 


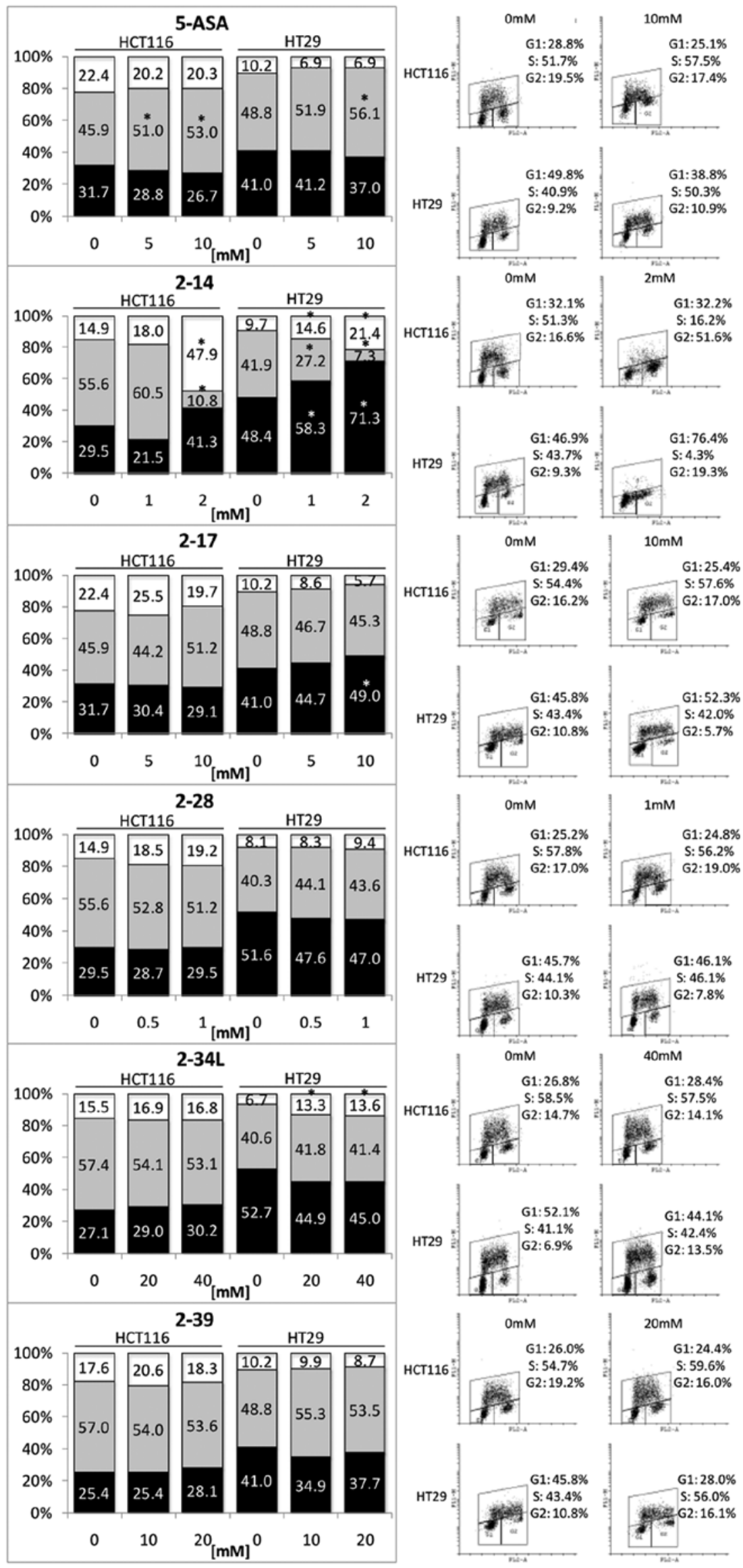

Figure 4. Effects of 5-ASA derivatives on cell cycle progression. HCT116 and HT29 cells were treated with different concentrations of 5-ASA and novel derivatives for $48 \mathrm{~h}$ followed by a BrdU-pulse and analysis by flow cytometry. Data are shown as mean changes in the G1- (black bars), S-phase- (grey bars) and G2-population (empty bars) for each compound in the left column. The right column shows representative pictures of control and treatment groups for each cell line and compound. Statistical analysis was performed using ANOVA and Tukey's HSD for post-hoc analysis. " $\mathrm{p}<0.05$ 


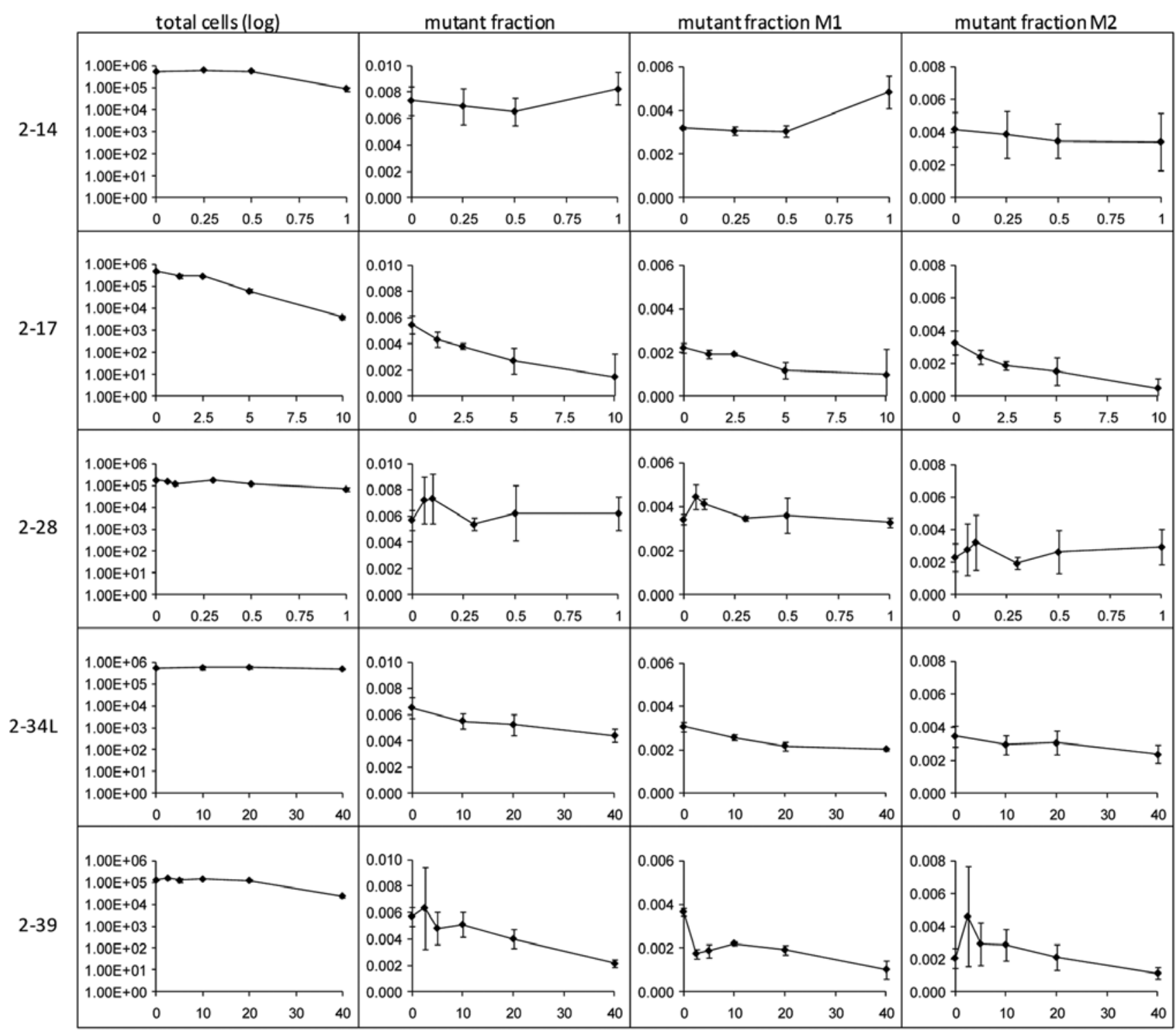

Figure 5. Effects of mesalazine derivatives on replication fidelity within a (CA)13 repeat. Non-fluorescent HCT116 A2.1 cells were sorted into 24-well plates and cultured for 7 days with various concentrations of mesalazine derivatives. The mutant fraction was calculated as the number of fluorescent cells per total cells. In a sub analysis of the experiments the mutant fraction was separately expressed for M1 cells (early mutation events immediately after the replication error) and M2 cells (definitive mutant cells). $\mathrm{x}$-axis: concentrations in mM. Cochran-Armitage trend tests were used to analyze the results for dose-dependent reductions in mutant fractions. Treatment with 2-17 ( $\chi^{2}$ statistics: $\left.12.81 ; \mathrm{p}=0.0003\right), 2-34 \mathrm{~L}\left(\chi^{2}\right.$ statistics: $\left.8.64 ; \mathrm{p}=0.0033\right)$ and $2-39\left(\chi^{2}\right.$ statistics: $\left.11.01 ; \mathrm{p}=0.0009\right)$ caused a dose-dependent reduction of mutant cell fractions. Both M1 fractions (2-17: $\chi^{2}$ statistics 8.1597; $\mathrm{p}=0.004283 ; 2-34 \mathrm{~L}: \chi^{2}$ statistics 11.1892, $\mathrm{p}=0.0008227 ; 2-39: \chi^{2}$ statistics: 10.2775, $\mathrm{p}=0.001347)$ and $\mathrm{M} 2$ fractions (2-17: $\chi^{2}$ statistics 13.1787, $\mathrm{p}=0.0002832$; 2-34L: $\chi^{2}$ statistics 4.598, $\mathrm{p}=0.03201 ; 2-39: \chi^{2}$ statistics 4.4488, $\left.\mathrm{p}=0.03493\right)$ were significantly reduced by the three compounds when analyzed separately.

checkpoint, and that changes in the position of the amino-group on the benzene ring influence the effect on cell cycle progression $(8,17)$. Therefore, we investigated the effects of novel mesalazine derivatives on cell cycle progression in p53-wild-type HCT116 and p53 mutant HT29 cells. Cells were treated with compounds for $48 \mathrm{~h}$, pulsed with BrdU and cell cycle was analysed by flowcytometry. Mesalazine, as previously described (17), led to an increased S-phase population in both cell lines. 2-14 caused a strong G2/M-arrest in HCT116 (14.9 to $47.9 \%$ at $2 \mathrm{mM}$; p<0.001) as well as some G0/G1 arrest. In p53 mutant HT29 cells 2-14 increased predominantly the G0/G1- $(48.4$ to $71.3 \%$; $<<0.001)$ and less the G2/M-population (9.7 to $21.4 \%$; $\mathrm{p}<0.001$ ). 2-17 caused an increase in the $\mathrm{G} 0 / \mathrm{G} 1$ population from 41 to $49 \%(\mathrm{p}=0.007)$ in HT29 cells, whereas 2-34L caused a dose-dependent G2/Marrest in this cell line (6.7 to $13.6 \%$ at $40 \mathrm{mM}$; $\mathrm{p}<0.001$ ). $2-28$ and 2-39 had no significant effects on cell cycle progression (Fig. 4). These data suggest that compounds 2-14, 2-17 and 2-34L are capable of inducing G0/G1 and G2/M cell cycle arrests in colon epithelial cells. However, in contrast to mesalazine (17), none of them induced an S-phase arrest.

2-17 and 2-34L improve replication fidelity. Mesalazine reduces replication errors at repetitive sequences in colon epithelial cell lines (16). We evaluated several novel mesalazine derivatives for their effects on the mutation rate at a $(\mathrm{CA}) 13$ repeat in mismatch repair (MMR) deficient HCT116 A2.1 cells. Cochran-Armitage 
Table I. Mutation rates at a (CA)13 microsatellite in HCT116 A2.1 cells, estimated by two different computational methods.

\begin{tabular}{|c|c|c|c|c|}
\hline \multirow[b]{2}{*}{ Treatment } & \multicolumn{2}{|c|}{ Method of the mean } & \multicolumn{2}{|c|}{ Maximum likelihood } \\
\hline & Control & Treated & Control & Treated \\
\hline 2-14 (1 mM) & $1.8 \pm 0.5$ & $2.1 \pm 0.8(117 \%)$ & $1.7 \pm 0.3$ & $1.7 \pm 0.4(100 \%)$ \\
\hline $2-17(5 \mathrm{mM})$ & $1.4 \pm 0.4$ & $1.2 \pm 0.6(86 \%)$ & $1.4 \pm 0.2$ & $1.1 \pm 0.4(79 \%)$ \\
\hline $2-28(1 \mathrm{mM})$ & $1.3 \pm 0.5$ & $1.9 \pm 0.8(146 \%)$ & $1.2 \pm 0.3$ & $1.8 \pm 0.5(150 \%)$ \\
\hline 2-34L (40 mM) & $1.5 \pm 0.3$ & $1.1 \pm 0.4(73 \%)$ & $1.5 \pm 0.2$ & $1.1 \pm 0.2(73 \%)$ \\
\hline $2-39(40 \mathrm{mM})$ & $1.2 \pm 0.5$ & $1.3 \pm 0.7(108 \%)$ & $1.2 \pm 0.3$ & $1.3 \pm 0.6(108 \%)$ \\
\hline
\end{tabular}

Data $\times 10^{-4}$ are mean \pm SE of mutation rates per microsatellite per generation. Drugs were used at the highest non-toxic concentration.

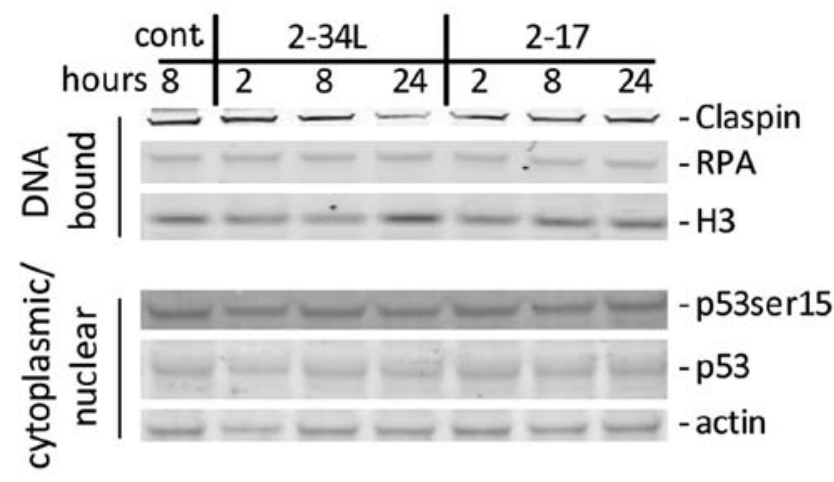

Figure 6. 2-34L and 2-17 do not cause accumulation of RPA and claspin on nuclear DNA nor do they phosphorylate 533 at Ser-15. Nuclear cell extracts from HCT116 cells treated with the novel mesalazine derivatives 2-34L $(40 \mathrm{mM})$ and 2-17 (12.5 mM) for 2, 8 and $24 \mathrm{~h}$, were processed for Western blotting and probed with claspin, RPA, p53ser15 and p53 antibodies. DNA-bound claspin was even reduced after $24 \mathrm{~h}$ of $2-34 \mathrm{~L}$ treatment.

trend tests revealed significant decreases in mutant fractions as the doses of 2-17, 2-34L and 2-39 increased, with $\chi^{2}$ statistics of $12.81(\mathrm{p}=0.0003)$ for $2-17,8.64(\mathrm{p}=0.0033)$ for $2-34 \mathrm{~L}$ and 11.01 $(\mathrm{p}=0.0009$ ) for $2-39$ (Fig. 5). 2-34L and 2-39 caused this effect mainly by reducing M1 cells $\left(\chi^{2}\right.$ statistics $11.19 ; \mathrm{p}=0.0008$ and $\chi^{2}$ statistics $\left.10.28 ; \mathrm{p}=0.0013\right) .2-17$ reduced M1 ( $\chi^{2}$ statistics 8.16; $\mathrm{p}=0.0043)$ and $\mathrm{M} 2$ cells $\left(\chi^{2}\right.$ statistics $\left.13.18 ; \mathrm{p}=0.0003\right)$ in a relevant amount. When mutation rates were calculated 2-17 $\left(1.4 \times 10^{-4} \pm 2 \times 10^{-5}\right.$ to $1.1 \times 10^{-4} \pm 4 \times 10^{-5} ; 79 \%$ of control) and $2-34 \mathrm{~L}$ $\left(1.5 \times 10^{-4} \pm 2 \times 10^{-5}\right.$ to $1.1 \times 10^{-4} \pm 2 \times 10^{-5} ; 73 \%$ of control) exhibited a positive effect on the improvement of replication fidelity (Table I).

Effects of 2-34L and 2-17 treatment on ATR/Chkl-pathway and p53 activation. Mesalazine induces an S-phase arrest, causes phosphorylation of p53 and leads to recruitment of RPA and claspin to DNA (17). Claspin is a cell cycle-regulated protein that associates with checkpoint kinase 1 (Chk1) upon localization onto DNA and phosphorylation by ATR (22) while RPA, which is required for the activation of ATR, binds to single stranded DNA (23). Nuclear/cytoplasmatic cell extracts and DNA bound protein fractions from HCT116 cells, treated with mesalazine derivatives $2-34 \mathrm{~L}(40 \mathrm{mM})$ and $2-17(12.5 \mathrm{mM})$ for 2, 8 and $24 \mathrm{~h}$, were processed for Western blotting and probed for claspin, RPA, p53ser15 and p53 antibodies, 24 hours after treatment with 2-34L DNA bound claspin decreased slightly (Fig. 6). This is in line with a reduced fraction of cells in replication phase (Fig. 4). Thus, in contrast to mesalazine (17) (data not shown) the improvement of replication fidelity by $2-34 \mathrm{~L}$ is not associated with activation of a replication checkpoint or the p53 and ATR/ Chk1 pathways.

\section{Discussion}

There is growing experimental and clinical evidence indicating that mesalazine has chemopreventive activity, in particular in the setting of UC $(4 ; 5)$. Recent studies on the molecular mechanisms behind the preventive effects have contributed to the understanding of molecular modes of action of this drug (3) and stimulated the development of derivatives in order to improve anti-oxidant, anti-inflammatory and anti-neoplastic activities (24).

In this study we compared the in vitro effects of five novel mesalazine derivatives (Fig. 1), which were designed with the goal of improving anti-inflammatory potency, with specific interest in replication fidelity using an in vitro assay for frameshift mutations (18). As previously shown for mono-, di- and tetranucleotide repeats mesalazine also improved replication fidelity in this study (25). Similar to mesalazine two out of five selected derivatives, 2-17 and 2-34L, also improved replication fidelity at a (CA)13 microsatellite. These findings, however, indicate that such improvement in replication fidelity may occur independently of replication stalling or S-phase arrest as observed by cell cycle studies and immunoblotting against RPA and claspin (17).

Two other derivatives which were included in our panel, 2-14 and 2-39, were also under investigation in an earlier study (24). In this study, Stolfi and coworkers focused on the anti-proliferative effect of mesalazine derivatives and found 2-14 to be the most active inhibitor of proliferation and a pan-caspase inhibitor did not prevent the 2-14-mediated cell growth arrest, suggesting that apoptosis is not the mechanism responsible for the reduced cell growth. 2-14 also caused a decrease of cyclin D1 and an accumulation of cells in G0/G1 phase (24). Similar to findings of Stolfi et al, in our study 2-14 was the most potent inhibitor of proliferation (with a similar $\mathrm{IC}_{50}$ ), being about 10 times as effective as mesalazine, which served as a control, whilst 2-39 showed only slight effect. We hereby confirmed the results of Stolfi et al using a different method. In HT29 and HCT116 
cells 2-14 caused an accumulation of cells in G0/G1 as well as in $\mathrm{G} 2 / \mathrm{M}$. This difference may be due to different cultivation periods or media conditions (24).

Mesalazine arrests CRC cells in S-phase (17). This effect is associated with the proteasome-mediated ubiquitination and degradation of CDC25A, a phosphatase that regulates the transition of S-phase (26). Mesalazine also leads to phosphorylation of $\mathrm{p} 53$ and to the recruitment of RPA and claspin onto the DNA (17). Claspin is a cell cycle-regulated protein that associates with checkpoint kinase 1 (Chk1) upon localization onto DNA and phosphorylation by ATR (22) while RPA, which is required for the activation of ATR, binds to single stranded DNA (23). DNA bound levels of claspin and RPA are increased in cells undergoing S-phase. We speculated that these effects are related to the mesalazine mediated improvement of replication fidelity. Surprisingly, we identified two novel mesalazine derivatives, 2-17 and 2-34, which improve replication fidelity but do not arrest cells in S-phase or lead to the activation of RPA or claspin. This observation suggests that the improvement of replication fidelity is not necessarily linked to a slowdown of replication. In the same context antioxidant properties were considered to play a role in the decrease of mutation rates within microsatellites (27). However, the 5-ASA analogs 3-ASA, 4-ASA or the metabolite N-acetyl-5-ASA are potent superoxide scavengers but do not improve replication fidelity (8). Similarly, 2-14 is a potent superoxide scavenger but does not interfere with replication fidelity. This strengthens our hypothesis that mechanisms other than ROS-scavenging are likely to account for an improvement of replication fidelity. Hence, the molecular mechanism behind improved replication fidelity mediated by such compounds remains unknown.

It is not known whether these compounds are also active in vivo. Mouse models for spontaneous CRC (APCmin/+), UC associated CRC (DSS induced colitis) and HNPCC (28) would be available for testing such compounds in vivo. In order to observe an improvement of replication fidelity we had to use a high concentration of compound 2-34L (40 mM). This might influence the ability to test such a compound in vivo because of the amount of drug needed. Here we show improved replication fidelity within a (CA)13 repeat by 2-17 and 2-34L but it is not known whether other microsatellite repeats or non-repetitive sequences are also preserved from replication errors.

In conclusion, our data show that the novel mesalazine derivatives 2-17 and 2-34L are capable of improving replication fidelity in vitro, a finding that might be relevant to CRC chemoprevention both in inflammatory bowel diseases and in hereditary non-polyposis colorectal cancer (HNPCC). The improvement in replication fidelity is independent on the type of cell cycle arrest, the activation of DNA damage pathways (such as p53 and ATR/Chk1) or the compound's anti-oxidant properties. Further studies need to address the molecular pathways for lowering frameshift mutations as well as testing of these derivatives in animal models of CRC (both for colitis-associated cancer and HNPCC).

\section{Acknowledgements}

We thank Dr Andreas Spittler and Guenther Hofbauer for cell sorting (Core Facility Flow Cytometry, Medical University of Vienna) and Giuliani S.p.A. for providing the mesalazine deriva- tives. The financial support by the Federal Ministry of Economy, Family and Youth and the National Foundation for Research, Technology and Development is gratefully acknowledged. This study was supported by the Austrian Science Fund (FWF grant P18270) and the Christian Doppler Research Association. Funding to pay the Open Access charge was provided by FWF.

\section{References}

1. Svartz N: Salazopyrin - a new sulfanilamide preparation. A. Therapeutic result in rheumatoid arthritis. B. Therapeutic results in ulcerative colitis. C. Toxic manifestations on treatment with sulfanilamide preparations. Acta Med Scand 110: 577-590, 1942.

2. Azad Khan AK, Piris J and Truelove SC: An experiment to determine the active therapeutic moiety of sulphasalazine. Lancet 2: 892-895, 1977.

3. Lyakhovich A and Gasche C: Systematic review: molecularchemoprevention of colorectal malignancy by mesalazine. Aliment Pharmacol Ther 31: 202-209, 2010.

4. Rubin DT, Cruz-Correa MR, Gasche C, Jass JR, Lichtenstein GR, Montgomery EA, Riddell RH, Rutter MD, Ullman TA, Velayos FS and Itzkowitz S: Colorectal cancer prevention in inflammatory bowel disease and the role of 5-aminosalicylic acid: a clinical review and update. Inflamm Bowel Dis 14: 265-274, 2008.

5. Stolfi C, Pellegrini R, Franze E, Pallone F and Monteleone G: Molecular basis of the potential of mesalazine to prevent colorectal cancer. World J Gastroenterol 14: 4434-4439, 2008.

6. Kennedy M, Wilson L, Szabo C and Salzman AL: 5-aminosalicylic acid inhibits iNOS transcription in human intestinal epithelial cells. Int J Mol Med 4: 437-443, 1999.

7. Stolfi C, Fina D, Caruso R, Caprioli F, Sarra M, Fantini MC, Rizzo A, Pallone F and Monteleone G: Cyclooxygenase-2dependent and -independent inhibition of proliferation of colon cancer cells by 5 -aminosalicylic acid. Biochem Pharmacol 75: 668-676, 2008.

8. Campregher C, Luciani MG, Biesenbach P, Evstatiev R, Lyakhovich $\mathrm{A}$ and Gasche $\mathrm{C}$ : The position of the amino group on the benzene ring is critical for mesalamine's improvement of replication fidelity. Inflamm Bowel Dis 16: 576-582, 2010.

9. Kaiser GC, Yan F and Polk DB: Mesalamine blocks tumor necrosis factor growth inhibition and nuclear factor kappaB activation in mouse colonocytes. Gastroenterology 116: 602-609, 1999.

10. Swidsinski A, Loening-Baucke V, Bengmark S, Lochs H and Dorffel Y: Azathioprine and mesalazine-induced effects on the mucosal flora in patients with IBD colitis. Inflamm Bowel Dis 13: 51-56, 2007.

11. Chu EC, Chai J, Ahluwalia A and Tarnawski AS: Mesalazine downregulates c-Myc in human colon cancer cells. A key to its chemopreventive action? Aliment Pharmacol Ther 25: 1443-1449, 2007.

12. Monteleone G, Franchi L, Fina D, Caruso R, Vavassori P Monteleone I, Calabrese E, Naccari GC, Bellinvia S, Testi R and Pallone F: Silencing of SH-PTP2 defines a crucial role in the inactivation of epidermal growth factor receptor by 5-aminosalicylic acid in colon cancer cells. Cell Death Differ 13: 202-211, 2006.

13. Rousseaux C, Lefebvre B, Dubuquoy L, Lefebvre P, Romano O, Auwerx J, Metzger D, Wahli W, Desvergne B, Naccari GC, Chavatte P, Farce A, Bulois P, Cortot A, Colombel JF and Desreumaux P: Intestinal antiinflammatory effect of 5-aminosalicylic acid is dependent on peroxisome proliferator-activated receptor-gamma. J Exp Med 201: 1205-1215, 2005.

14. Bos CL, Diks SH, Hardwick JC, Walburg KV, Peppelenbosch MP and Richel DJ: Protein phosphatase $2 \mathrm{~A}$ is required for mesalazine-dependent inhibition of Wnt/beta-catenin pathway activity. Carcinogenesis 27: 2371-2382, 2006.

15. Reinacher-Schick A, Schoeneck A, Graeven U, SchwarteWaldhoff I and Schmiegel W: Mesalazine causes a mitotic arrest and induces caspase-dependent apoptosis in colon carcinoma cells. Carcinogenesis 24: 443-451, 2003.

16. Gasche C, Goel A, Natarajan L and Boland CR: Mesalazine improves replication fidelity in cultured colorectal cells. Cancer Res 65: 3993-3997, 2005.

17. Luciani MG, Campregher C, Fortune JM, Kunkel TA and Gasche C: 5-ASA affects cell cycle progression in colorectal cells by reversibly activating a replication checkpoint. Gastroenterology 132: 221-235, 2007. 
18. Gasche C, Chang CL, Natarajan L, Goel A, Rhees J, Young DJ, Arnold CN and Boland CR: Identification of frame-shift intermediate mutant cells. Proc Natl Acad Sci USA 100: 1914-1919, 2003.

19. Campregher C, Luciani MG and Gasche C: Activated neutrophils induce an hMSH2-dependent G2/M checkpoint arrest and replication errors at a (CA)13-repeat in colon epithelial cells. Gut 57: 780-787, 2008

20. Natarajan L, Berry CC and Gasche C: Estimation of spontaneous mutation rates. Biometrics 59: 555-561, 2003

21. Hussain SP, Hofseth LJ and Harris CC: Radical causes of cancer. Nat Rev Cancer 3: 276-285, 2003.

22. Chini CC and Chen J: Human claspin is required for replication checkpoint control. J Biol Chem 278: 30057-30062, 2003.

23. Lee J, Kumagai A and Dunphy WG: Claspin, a Chk1-regulatory protein, monitors DNA replication on chromatin independently of RPA, ATR, and Rad17. Mol Cell 11: 329-340, 2003.

24. Stolfi C, Sarra M, Caruso R, Fantini MC, Fina D, Pellegrini R, Palmieri G, Macdonald TT, Pallone F and Monteleone G: Inhibition of colon carcinogenesis by 2 -methoxy-5-amino-N-hydroxybenzamide, a novel derivative of mesalamine. Gastroenterology 138: 221-230, 2010.
25. Campregher $\mathrm{C}$, Honeder C, Chung H, Carethers JM and Gasche C: Mesalazine reduces mutations in transforming growth factor beta receptor II and activin type II receptor by improvement of replication fidelity in mononucleotide repeats. Clin Cancer Res 16: 1950-1956, 2010.

26. Stolfi C, Fina D, Caruso R, Caprioli F, Fantini MC, Rizzo A, Sarra M, Pallone F and Monteleone G: Mesalazine negatively regulates $\mathrm{CDC} 25 \mathrm{~A}$ protein expression and promotes accumulation of colon cancer cells in S phase. Carcinogenesis 29: 1258-1266, 2008.

27. Glaab WE, Hill RB and Skopek TR: Suppression of spontaneous and hydrogen peroxide-induced mutagenesis by the antioxidant ascorbate in mismatch repair-deficient human colon cancer cells. Carcinogenesis 22: 1709-1713, 2001.

28. Kucherlapati MH, Lee K, Nguyen AA, Clark AB, Hou H Jr, Rosulek A, Li H, Yang K, Fan K, Lipkin M, Bronson RT, Jelicks L, Kunkel TA, Kucherlapati R and Edelmann W: An Msh2 conditional knockout mouse for studying intestinal cancer and testing anticancer agents. Gastroenterology 138: 993-1002, 2010. 